\section{Degradation and detoxification of 2-chlorophenol aqueous solutions using ionizing gamma radiation}

\begin{abstract}
Chlorophenols are compounds with high toxicity, poor biodegradability, and carcinogenic and recalcitrant properties. This work studies, for the first time, the destruction and detoxification of 2-chlorophenol (2-CP) in water using ${ }^{60} \mathrm{Co}$ gamma radiation under different conditions including varied radiation doses, addition of hydrogen peroxide $\left(\mathrm{H}_{2} \mathrm{O}_{2}\right)$, and varied $\mathrm{pH}$ values. High-performance liquid chromatography (HPLC) and ion chromatography (IC) confirmed a successful degradation of 2-CP to primarily yield phenol molecules and chloride anions. A radiation dose as low as $25 \mathrm{kGy}$ achieved approximately $90 \%$ removal of $50-150 \mathrm{ppm}$ of 2-CP in neutral water. However, the addition of a strong oxidizer such as $\mathrm{H}_{2} \mathrm{O}_{2}$ to 2-CP solutions reduced the required dose to achieve $90 \%$ removal to at least 1.3 -fold. The reduction in radiation doses was also observed in acidic and alkaline media, reducing the required doses of $90 \%$ removal to at least 0.4 -fold. It was imperative to study the toxicity levels of the oxidation by-products to provide directions for the potential applicability of this technology in water treatment. Toxicology Microtox ${ }^{\circledast}$ bioassay indicated a significant reduction in the toxicity of the degradation by-products and the detoxification was further enhanced by the addition of $\mathrm{H}_{2} \mathrm{O}_{2}$ and changing the $\mathrm{pH}$ to more acidic or alkaline conditions. These findings will contribute to the knowledge of the removal and detoxification of such challenging environmental contaminant and could be potentially applied to other biologically resistant compounds.
\end{abstract}

Keywords: 2 -chlorophenol $\bullet$ degradation $\bullet$ detoxification $\bullet$ gamma irradiation $\bullet$ aqueous solution

\author{
A. A. Basfar ${ }^{\bowtie}$, M. Muneer, O. A. Alsager \\ Radiation Technology Centre, \\ Atomic Science Research Institute, \\ King Abdulaziz City for Science and Technology, \\ P. O. Box 6086, Riyadh 11442, Saudi Arabia, \\ E-mail: abasfar@kacst.edu.sa
}

Received: 3 April 2016

Accepted: 25 July 2016

\section{Introduction}

Chlorophenols are widely used in various industries, including as preservatives in wood manufacturing, in paper industry, in chemical synthesis, and in biodegradation of herbicide and pesticide [1]. These applications lead to considerable level of contamination in wastewater and ground water [2]. Chlorophenols are highly toxic, poorly biodegradable, and present serious health concerns to human and to the environment [3]. Thus, they have been included in both U.S. Environmental Protection Agency and European Union list of priority pollutants [4].

The search for clean, fresh, and potable water has always been a priority for mankind. The permanent threat to natural environments, resulting from industrial activity and municipal infrastructures, draws significant attention on the development of efficient technologies for the removal of anthropogenic pollutants and complete destruction of toxic compounds $[5,6]$. Traditional wastewater treatment methods such as chlorination, adsorption, coagulation, filtration, sedimentation, adsorption on activated carbon, ultrafiltration, reverse osmosis, and electrocoagulation are versatile and useful technologies [7]. However, they have certain limitations such 
as high cost, technologically deficit, non-destructive, incomplete degradation, and phase change rather than removal and require further treatment $[7,8]$.

There is a pressing need for an effective, innovative, cheap, non-selective treatment method to overrule all existing water treatment problems [9]. Numerous methods can be used for the removal of various classes of pollutants from contaminated environmental components. Particularly, advanced oxidation processes (AOPs) include UV photolysis, Fenton, photo-Fenton, ozonation, sonolysis, and photocatalytic approaches $[10,11]$. These processes are easy to handle and yield significantly less residual products compared with conventional treatment methods $[10,11]$. Highly reactive hydroxyl radicals $\left(\mathrm{OH}^{\circ}\right)$, produced in situ during AOPs, are traditionally thought to be the active species responsible for the destruction of pollutants and break down of complex organic molecules into simpler and less toxic radiolytic fragments, through chain oxidation reactions [12].

AOP technologies appear to be a promising field of study. They have been reported to be effective for the degradation of soluble organic contaminants in water such as organophosphorus pesticides [13], antibiotics [14], coloured dyes [15], endocrine disrupting chemicals, and pharmaceutical residues [16].

Furthermore, the oxidizing hydroxyl radicals used for pollutant destruction can also be generated more readily using gamma radiation source such as ${ }^{60} \mathrm{Co}$ or electron beam. Gamma irradiation has been recently used for radiolytic degradation of pollutants in natural, waste, and drinking waters [17-20].

The main objective of this study was to comprehensively explore the potential of ionizing gamma radiation for the destruction of a chlorophenolic compound, which is 2-chlorophenol (2-CP). Previous attempts to decompose and remove other chlorophenolic residues from water were accomplished using non-readily and complicated procedures that produce the oxidizing hydroxyl radicals. These methods include processes based on hydrogen peroxide, photolysis, photocatalysis, and ozone, reviewed by Esplugas et al. [21]. The investigation of the degradation of chlorophenolic compounds including 2-CP using gamma irradiation from ${ }^{60} \mathrm{Co}$ was reported by other studies and was limited to (a) single target concentration and lacked vital information regarding the relation between target concentration and absorbed doses, (b) not studying the effect of changing the $\mathrm{pH}$ value on radiolytic degradation, (c) not covering the effect of adding a strong oxidizing agent such as $\mathrm{H}_{2} \mathrm{O}_{2}$ on 2-CP degradation efficiency, and (d) not investigating the toxicity of degradation by-products in varied $\mathrm{pH}$ media or under the effect of a strong oxidizing agent such as $\mathrm{H}_{2} \mathrm{O}_{2}$ [22-26] and others. These limitations are overcome by the present study. It was demonstrated that gamma irradiation alone from ${ }^{60} \mathrm{Co}$ source with the absorbed doses as low as $25 \mathrm{kGy}$ is sufficient to remove $90 \%$ of $2-\mathrm{CP}$ at an initial concentration in the range of $50-150 \mathrm{ppm}$ in water. Our results indicated that this removal can be accomplished at low irradiation doses in acidic or alkaline media or by introducing $\mathrm{H}_{2} \mathrm{O}_{2}$ to the ir- radiated solutions. It was also demonstrated that the toxicity of radiolytic degradation by-products was greatly reduced by using toxicology Microtox ${ }^{\circledR}$ bioassay. The toxicity studies were extended to cover various experimental conditions.

\section{Material and methods}

\section{Chemicals}

2-CP and phenol were procured from Merck, Germany, with $97 \%$ and $99 \%$ purity, respectively. Acetonitrile of high-performance liquid chromatography (HPLC) grade was supplied by Acros, New Jersey, USA. $\mathrm{H}_{2} \mathrm{O}_{2}$ was supplied by Scherlu, Germany. Hydrochloric acid and sodium hydroxide were procured from Merck, Germany. Acetic acid with $99.5 \%$ purity was procured from BDH Limited Pool England, UK. All reagents and solutions used for toxicity measurements were purchased from Microtox-sdi, USA. Stock solutions of 2-CP and phenol were made in distilled water followed by dilution to obtain the desired initial concentrations in distilled water. Double-distilled water was obtained from Barnstead E-Pure ${ }^{\mathrm{TM}}$ system (USA).

\section{Apparatus}

\section{Irradiation sources}

A cobalt- 60 gamma rays source model Gamma Cell 220 from MDS Nordion, Canada, was used for all irradiation studies. The source was calibrated using aqueous ferrous sulphate (Fricke dosimetry) solution [27]. Dose rate was $9.83 \mathrm{kGy} \cdot \mathrm{h}^{-1}$ and transit dose was estimated to be $12.7 \mathrm{~Gy} \cdot \mathrm{s}^{-1}$. All of the irradiations were conducted at room temperature, $23^{\circ} \mathrm{C}$.

\section{High-performance liquid chromatography (HPLC)}

2-CP and phenol were performed by reversed-phase HPLC using a Shimadzu chromatograph (10AD VP) with UV-VIS detector (SPD-10AV VP) fixed to $280 \mathrm{~nm}$ wavelength. A C18 analytical column and a guard column from Phenomenex (Torrance, CA, USA) were used to conduct the separation of two targeted compounds. The eluent used was a mixture of acetic acid $(43.7 \mathrm{mM})$ and acetonitrile in the ratio 55:45 with flow rate of $1 \mathrm{ml} \cdot \mathrm{min}^{-1}$ [28]. The sample injection volume was $20 \mu \mathrm{l}$. The 2-CP peak was obtained at a retention time of $8.7 \mathrm{~min}$, while the phenol peak appeared at $2.7 \mathrm{~min}$.

\section{Ion chromatography (IC)}

Dionex DX-500 ion chromatograph from Dionex, USA, equipped with conductivity detector (CDD-10A VP, Shimadzu, Japan) and analytical column (Shim-pack IC-A3, $4.6 \mathrm{~mm} \times 15 \mathrm{~cm}$ ), was used to determine the concentrations of chlorine anion. The eluent used was a mixture of $8 \mathrm{mM}$ of P-hydroxybenzoic acid and 3.2 mM bis-tris ((2-hy- 
droxyethyl) imino-tris (hydroxyl methyl) methane) with flow rate of $1.2 \mathrm{ml} \cdot \mathrm{min}^{-1}$ under an oven temperature of $37^{\circ} \mathrm{C}$. At these conditions, the retention time of chlorine anion was observed at $4.6 \mathrm{~min}$.

\section{Procedures}

The desired concentrations of 2-CP $(50,100$, and $150 \mathrm{ppm}$ ) were made in double-distilled water and then placed in 40-ml airtight cap vials followed by irradiation at the selected doses. Different experimental conditions were investigated to explore their effects on 2-CP radiolytic degradation and detoxification. These conditions are absorbed doses, initial concentration, $\mathrm{pH}$ media, chloride ion formations in water radiolysis, and concentration of hydrogen peroxide $\left(\mathrm{H}_{2} \mathrm{O}_{2}\right)$. Immediately after irradiation, HPLC under the previously mentioned conditions was used for analyzing the irradiated and non-irradiated samples. All irradiation studies were carried out in doublets and compared to the corresponding non-irradiated controls. The average was calculated to describe the degradation of the 2-CP in tested aqueous solutions. Similarly, toxicity measurements were performed for control as well as irradiated samples and were compared. For $\mathrm{pH}$ adjustment, diluted solutions of sodium hydroxide $(\mathrm{NaOH})$ and hydrochloric acid $(\mathrm{HCl})$ were used to adjust the selected initial $\mathrm{pH}$ of 2-CP solutions (ranged from 4 to 9). For the experiments with $\mathrm{H}_{2} \mathrm{O}_{2}$, stock solution of $\mathrm{H}_{2} \mathrm{O}_{2}$ was directly introduced into the targeted samples at selected concentrations and then the samples were subjected to irradiation.

\section{G-value}

Removal efficiency, G-value of 2-chlorophenol (defined by the number of molecules formed (or destroyed) in solution absorbing $100 \mathrm{eV}$ (radiation energy) was calculated at each absorbed dose using Eq. (1) [29]:

$$
\mathrm{Gd}=\frac{[R] N_{\mathrm{A}}}{\mathrm{D}\left(6.24 \times 10^{17}\right)}
$$

where $[R]$ is the change in 2-chlorophenol concentration $\left[\mathrm{mol} \cdot \mathrm{l}^{-1}\right]$ at given dose, $D$ is the absorbed dose [Gy], $6.24 \times 10^{17}$ is the conversion factor from Gy to $100 \mathrm{eV} \cdot \mathrm{l}^{-1}$, and $N_{\mathrm{A}}$ is Avogadro's number (6.02 $\left.\times 10^{23}\right)$. The change in G-value was used to evaluate the effect of 2-CP concentration, $\mathrm{pH}$ (acidic and basic), and oxidizer (hydrogen peroxide).

\section{Dose constant}

The dose constant, $\mathrm{K}$, is the slope of the line of natural logarithm $(\mathrm{ln})$ of the 2-CP concentration $[\mu \mathrm{M}]$ vs. dose $[\mathrm{kGy}]$. These dose constants were used to calculate the dose required for $50 \%$ and $90 \% 2-\mathrm{CP}$ degradation $\left(\mathrm{D}_{0.5}\right.$ and $\mathrm{D}_{0.9}$ values) using Eqs. (2) and (3) [29].

$$
\begin{aligned}
& \mathrm{D}_{0.5}=\frac{\ln }{\mathrm{K}} \\
& \mathrm{D}_{0.9}=\frac{\ln }{\mathrm{K}}
\end{aligned}
$$

\section{Toxicity measurements}

The Microtox ${ }^{\circledR}$ test based on bioluminescent marine bacterium Vibrio fischeri was performed in order to evaluate the potential toxicity for the irradiated 2-CP solutions. Measurement of toxicity was performed within $24 \mathrm{~h}$ after irradiation. In our investigation, the toxicity was tested after $15 \mathrm{~min}$ of exposure. Two per cent $\mathrm{NaCl}$ solution was used as reference solution to calculate bacterial light intensity. Owing to potential toxicity of $\mathrm{H}_{2} \mathrm{O}_{2}$, less than $1 \mathrm{mg}$ $\mathrm{MnO}_{2} \mathrm{ml}^{-1}$ was added to the irradiated solutions and kept for $1 \mathrm{~h}$ to eliminate residual effect of $\mathrm{H}_{2} \mathrm{O}_{2}$ from irradiated samples [30]. The effective concentration value that is needed to reduce the bacterial luminescence by $50 \%$ (EC50) was calculated from the change in the luminescence intensity in the treated samples [31-33].

\section{Results and discussion}

\section{Effects of different conditions on radiolytic degradation of 2-CP}

\section{Initial concentration and irradiation dose}

As can be seen in Fig. 1, there is a gradual increase in the removal of 2-CP as the irradiation doses increase, which is consistent with previous studies $[17,34]$. A removal of at least $90 \%$ has been achieved for the entire range of 2-CP concentrations. Notably, the lower concentration of 2-CP showed greater degradation and hence higher removal. This can be understood by considering the stoichiometry of the oxidation reaction. For example, a given ionizing radiation dose produces a given amount of

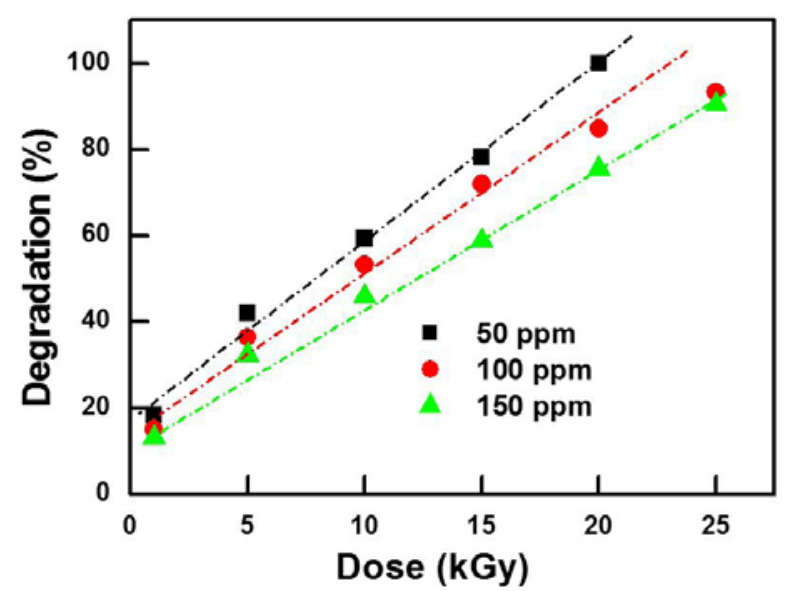

Fig. 1. Degradation of different 2-CP concentrations (50, 100 , and $150 \mathrm{ppm}$ ) under varied gamma irradiation doses. The $\mathrm{pH}$ of the solutions was 6.8. Data were fitted with straight lines to guide the eye. 
Table 1. Removal efficiency and dose constants for the degradation of 2-CP aqueous solutions at $\mathrm{pH} 6.8$

\begin{tabular}{|c|c|c|c|c|c|}
\hline \multirow{2}{*}{$\begin{array}{c}2-\mathrm{CP} \\
{[\mathrm{ppm}]}\end{array}$} & \multirow{2}{*}{$\begin{array}{c}\text { Dose } \\
{[\mathrm{kGy}]}\end{array}$} & \multirow{2}{*}{$\begin{array}{l}\text { G-value } \\
{\left[\mu \mathrm{m} \cdot J^{-1}\right]}\end{array}$} & \multicolumn{3}{|c|}{ Parameter } \\
\hline & & & $\mathrm{K}$ & $\mathrm{D}_{50}[\mathrm{kGy}]$ & $\mathrm{D}_{90}[\mathrm{~Gy}]$ \\
\hline 50 & $1-20$ & $0.0120-0.687$ & 0.1130 & 6.79 & 18.56 \\
\hline 100 & $1-25$ & $0.0254-1.267$ & 0.0925 & 9.49 & 20.55 \\
\hline 150 & $1-25$ & $0.0677-1.474$ & 0.0845 & 12.37 & 24.65 \\
\hline
\end{tabular}

$\mathrm{OH}^{\bullet}$ radicals that will completely oxidize a given concentration of 2-CP and in contrast will result in an incomplete reaction for higher concentrations. The required doses to decompose $50 \%$ and $90 \%$ of 2-CP $\left(\mathrm{D}_{50}\right.$ and $\left.\mathrm{D}_{90}\right)$ were calculated. Consistent with our observation in Fig. 1, the results in Table 1 clearly demonstrate that higher concentrations of 2-CP require higher doses and vice versa. Evidently, $\mathrm{D}_{50}$ and $\mathrm{D}_{90}$ are higher for $150 \mathrm{ppm}(12.37$ and $24.65 \mathrm{kGy}$, respectively) than that for $50 \mathrm{ppm}$ (6.79 and $18.56 \mathrm{kGy}$, respectively).

The removal efficiency of 2-CP can be quantitatively described in terms of G-value. Data in Table 1 suggests that the calculated G-values for the irradiated concentrations of 2-CP at different doses are dependent on concentration and irradiation dose. Two main trends can be observed from the $\mathrm{G}$-values in Table 1 . At a given $2-\mathrm{CP}$ concentration, the $\mathrm{G}$-value $\left[\mu \mathrm{mol} \cdot \mathrm{J}^{-1}\right]$ decreases with increasing irradiation dose. However, across the investigated 2-CP concentrations, G-value increases with increased 2-CP concentration. These relationship results support our observation in Fig. 1 and the calculated $D_{50}$ and $\mathrm{D}_{90}$ values listed in Table 1 . The higher 2-CP concentration requires higher irradiation dose to achieve complete decomposition.

From our initial investigation, the concentration of 2-CP was found to be a crucial factor that significantly influence the degradation efficiency.

\section{$\mathrm{H}_{2} \mathrm{O}_{2}$ oxidizer}

For commercial application of gamma irradiation technology in water and wastewater treatment plants, low irradiation doses are highly favoured to be economically feasible [10]. $\mathrm{H}_{2} \mathrm{O}_{2}$ is a powerful oxidizer commonly used for wastewater treatment [35]. Coupling AOPs with $\mathrm{H}_{2} \mathrm{O}_{2}$ has been proven to improve the degradation efficiency and reduce the required irradiation doses [33, 36]. But this is the first time that irradiation treatment is coupled with the use of $\mathrm{H}_{2} \mathrm{O}_{2}$ for removal of 2-CP in water solutions.

2-CP at a concentration of $100 \mathrm{ppm}$ in neutral $\mathrm{pH}$ solutions ( $\mathrm{pH}$ of 6.8 ) was selected to study the effect of adding the strong oxidizing agent $\mathrm{H}_{2} \mathrm{O}_{2}$ on the radiolytic degradation behaviour. Figure 2 shows that gradual increase in the concentration [\%] of $\mathrm{H}_{2} \mathrm{O}_{2}$ in the tested 2-CP solutions resulted in a significant enhancement in the removal efficiency of the target molecule. This is evident from our observation that the required irradiation doses for $50 \%$ and $90 \%$ degradation $\left(\mathrm{D}_{50}\right.$ and $\left.\mathrm{D}_{90}\right)$ was reduced from 9.49 and $20.55 \mathrm{kGy}$ (calculated in Table 1) to at least 2.08 and $6.93 \mathrm{kGy}$, respectively, by adding $\mathrm{H}_{2} \mathrm{O}_{2}$. Therefore, the addition of $\mathrm{H}_{2} \mathrm{O}_{2}$ seems to

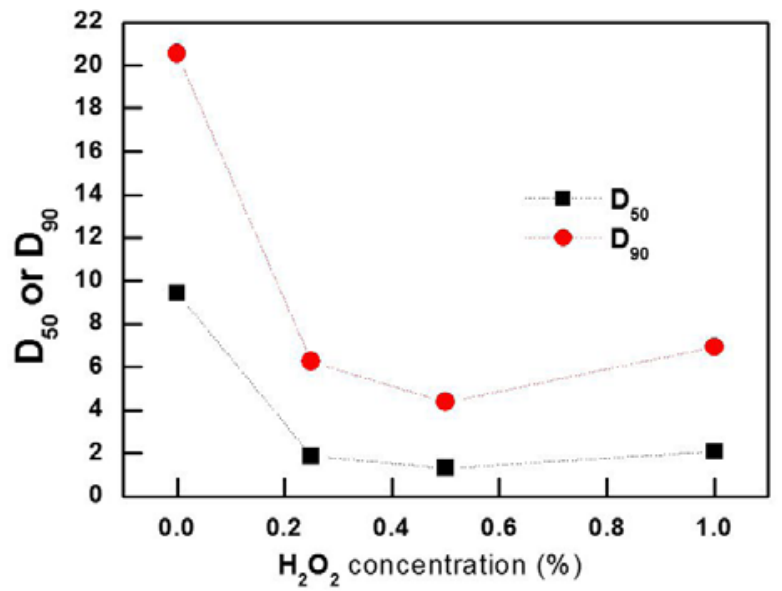

Fig. 2. Effect of $\mathrm{H}_{2} \mathrm{O}_{2}$ concentration on the removal efficiency of $100 \mathrm{ppm} 2-\mathrm{CP}$ at a pH of 6.8, represented as $\mathrm{D}_{50}$ and $\mathrm{D}_{90}$.

have a positive effect on the radiolytic degradation of 2-CP. It should be noted that no further improvement in the removal efficiency was observed upon increasing the concentration of $\mathrm{H}_{2} \mathrm{O}_{2}$ beyond $0.5 \%$ (Fig. 2), which could be due to the scavenging effect of excess $\mathrm{H}_{2} \mathrm{O}_{2}$ on hydroxyl radicals [37]. Hence, this particular $\mathrm{H}_{2} \mathrm{O}_{2}$ concentration is recommended for similar experimental conditions.

It is known that scavenging the hydrated electron $\left(\mathrm{e}_{\mathrm{aq}}^{-}\right)$and hydrogen atom $\left(\mathrm{H}^{\circ}\right)$ during AOP is necessary because these species significantly decline the degradation efficiency of a given target molecule $[13,21,35]$. In the present work, stronger oxidizing conditions can be enhanced by adding $\mathrm{H}_{2} \mathrm{O}_{2}$ that scavenges the reducing species $\mathrm{e}^{-}$aq and $\mathrm{H}^{\circ}$ and consequently explains the enhanced degradation behaviour seen in Fig. 2. Complete degradation of 2-CP was achieved by the interaction of free hydroxyl radicals with the solute molecules which is in agreement with the reported data for other phenolic compounds [33, 38].

\section{pH of aqueous solutions}

2-CP with a concentration of $100 \mathrm{ppm}$ was selected to evaluate the effect of $\mathrm{pH}$ values on the degradation efficiency. Figure 3 shows the degradation efficiency as a function of absorbed dose. Both acidic and alkaline conditions ( $\mathrm{pH} 4$ and $\mathrm{pH}$ 9) enhanced the degradation efficiencies in comparison to the neutral $\mathrm{pH}$. However, the degradation enhancement associated with $\mathrm{pH} 4$ was greater than $\mathrm{pH} 9$. Evidently, $\mathrm{D}_{50}$ and $\mathrm{D}_{90}$ were reduced upon increasing the acidity or alkalinity and the reduction was greater with the acidic conditions. For example, the $\mathrm{D}_{50}$ was reduced from 9.49 to 4.78 and $6.41 \mathrm{kGy}$ when the $\mathrm{pH}$ was changed to 4 and 9 , respectively. Similarly, 


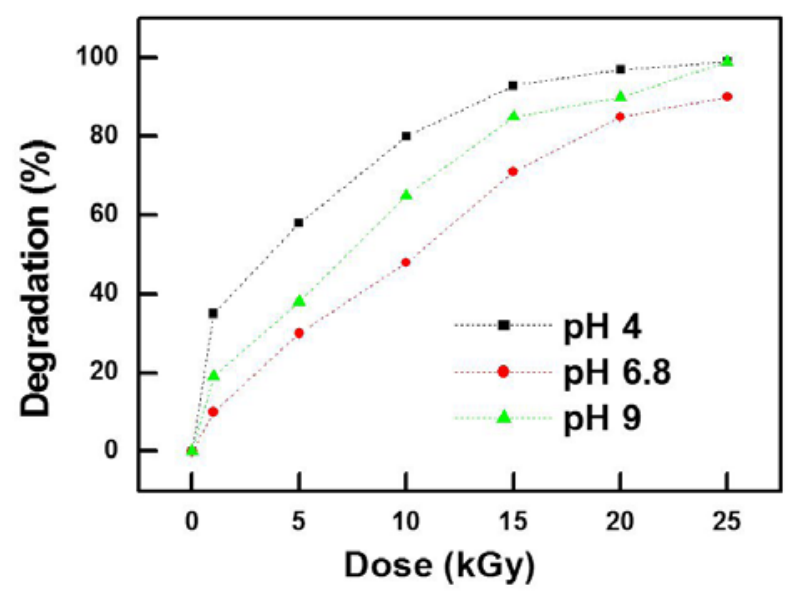

Fig. 3. Effect of the $\mathrm{pH}$ of the solution on the degradation of $2-\mathrm{CP}$ at a concentration of $100 \mathrm{ppm}$.

$\mathrm{D}_{90}$ of the neutral $\mathrm{pH}$ decreased from 20.55 to 14.95 and $18.72 \mathrm{kGy}$ upon changing the $\mathrm{pH}$ to acidic or alkaline, respectively.

The greater reduction in the required absorbed dose for 2-CP degradation at $\mathrm{pH} 4$ in comparison to other media can be attributed to the enhanced release of chloride ions in the acidic condition. The pKa of 2-CP falls in the range 8.3-8.6 [1], which indicates that the molecule will be protonated at $\mathrm{pH} 4$ and will aid the release of $\mathrm{Cl}^{-1}$. However, the enhancement in 2-CP degradation observed in the alkaline conditions can attribute the scavenging effect of $\mathrm{OH}$ ions that terminates the reducing species such as the hydrated electron $\left(\mathrm{e}^{-}{ }_{\mathrm{aq}}\right)$ and hydrogen atom $\left(\mathrm{H}^{\bullet}\right)$.

\section{Analysis of degradation by-products in irradiated samples}

As clearly demonstrated, 2-CP can be decomposed efficiently under ionizing gamma irradiation, which fulfils the primary objective of the present work. The secondary purpose of this study was to identify the degradation by-products and examine the toxicity levels after irradiation. These objectives are particularly crucial for commercial application of ionizing radiation in water and wastewater treatments. The decomposition of 2-CP at low doses resulted in the formation of phenol molecules and chloride ions, as shown in Scheme 1. These by-products were identified using HPLC and ion chromatography (IC) as described in details in the experimental section. Higher irradiation doses yielded simpler and unidentified by-products in addition to chloride ions (Scheme 1).

The formation of phenol and chloride ions were determined in the irradiated 2-CP aqueous solutions

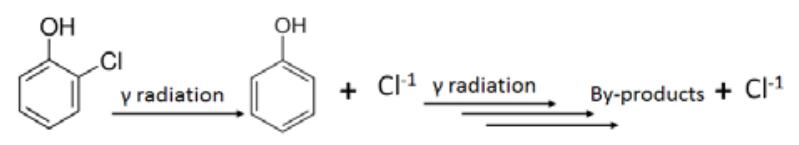

Scheme 1. Radiolytic degradation of 2-CP to phenol and chloride ion and further decomposition to other by-products at irradiation doses.

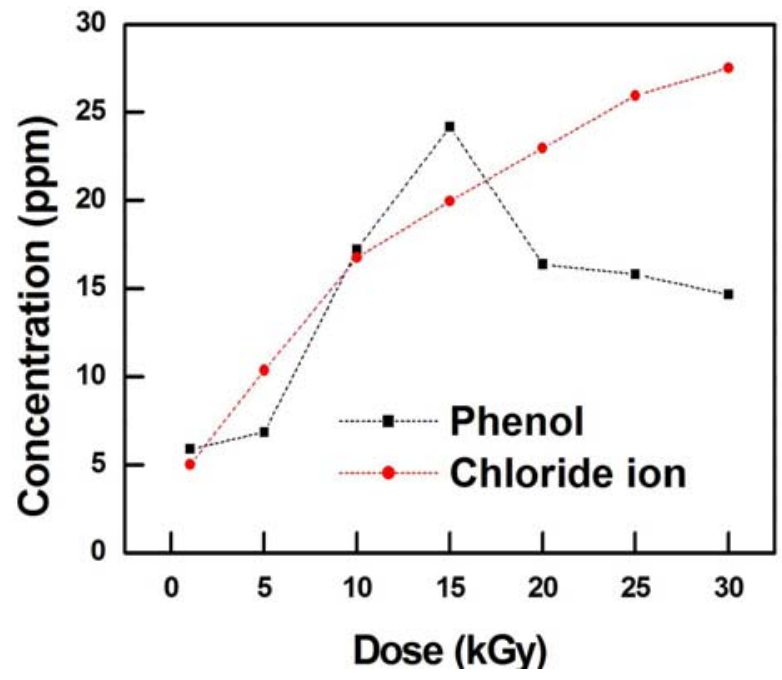

Fig. 4. HPLC and IC quantification of phenol and chloride ions resulting from irradiating 2-CP (concentration of $100 \mathrm{ppm}$ and $\mathrm{pH}$ of 6.8 ) with increasing doses.

at $\mathrm{pH} 6.8$ and in the presence of hydrogen peroxide. Figure 4 shows the formation of phenol and chloride ion in the irradiated solutions, of $\mathrm{pH} 6.8$ with no $\mathrm{H}_{2} \mathrm{O}_{2}$, as a function of increasing absorbed doses. Chloride ion concentration increased progressively with increasing doses, to reach a maximum release of $27 \%$ of the original $2-\mathrm{CP}$ concentration $(100 \mathrm{ppm})$. Zona et al. reported that almost $100 \%$ of chloride ions were released upon treating 2-CP with gamma irradiation [33]. The differences observed here could be attributed to the different experimental conditions conducted by the authors including lower 2-CP concentration (50 ppm) and higher $\mathrm{pH}(8-9)$. Additionally, chloride ions could undergo further reactions to form insoluble products or species that cannot be detected by the IC.

On the other hand, the concentrations of phenol increased up to $24 \mathrm{ppm}$ at $15 \mathrm{kGy}$ and decreased slightly at the remaining irradiation doses (20-30 kGy). These results suggest that higher irradiation doses not only cause the removal of chloride ions from 2-CP but also lead to the formation of other radiolytic products such as benzene ring. Our observation in this study is consistent with previous decomposition studies of other phenolic compounds conducted with different AOPs [21, 34].

From our initial studies with $\mathrm{H}_{2} \mathrm{O}_{2}$, the optimum degradation enhancement of 2-CP associated with $\mathrm{H}_{2} \mathrm{O}_{2}$ concentration of $0.5 \%$. Thus, this concentration was used for the identification of irradiation by-products. The results of phenol and chloride ion formation are unexpectedly different from those observed in Fig. 4 with neutral pH. The concentrations of phenol and chloride ion were only detectable at the initial irradiation doses beyond which the concentrations were below the detection limit of HPLC and IC. The resolved concentrations of phenol and chloride ion are 25 and 12 ppm and 9 and 26 ppm, respectively, for irradiation doses of 1 and $5 \mathrm{kGy}$, respectively. Phenol molecules can be further oxidized to simpler products such as benzene rings at higher irradiation doses that explains the inability 
to detect phenol at irradiation dose higher than $5 \mathrm{kGy}$. However, chloride ions are the simplest form of this species and can go no further decomposition. Under $\mathrm{H}_{2} \mathrm{O}_{2}$ condition, the formation of $\mathrm{Cl}^{-1}$ could be followed by recombination with other volatile or insoluble species [34] that prevent the detection by IC.

\section{Toxicity examinations}

The principal aim of the irradiation treatment of various pollutants does not necessarily require complete mineralization and removal but sufficient reduction of the toxicity presented by pollutants [29]. Furthermore, it is widely known that radiolytic degradation of organic pollutants in some cases may lead to the formation of more toxic products than the original substances $[1,3]$. Hence, monitoring of toxicity changes during radiolytic degradation of $2-\mathrm{CP}$ is essential for the qualifications of the irradiation treatment of toxicity for environmental protection. In this study, we used Microtox ${ }^{\circledR}$ bacterial tests to evaluate the toxicity of 2-CP under various experimental conditions. Microtox is widely used for toxicity examination and relies on using luminescent $V$. fischeri bacteria $[31,32]$. This type of bacteria was particularly selected because of its high sensitivity towards most organic toxicant, high reproducibility, and rapid test results [39].

\section{Effects of ionizing gamma radiation on toxicity of $2-C P$}

For these experiments, 2-CP at a concentration of $100 \mathrm{ppm}$ in neutral $\mathrm{pH}$ solutions was irradiated at the previously determined $\mathrm{D}_{50}$ and $\mathrm{D}_{90}$ doses, and at additional higher radiation doses. The effective concentration value that is needed to reduce bacterial luminescence by 50\% (EC50) was calculated from the change in the luminescence intensity in the treated samples [31-33]. Figure 5 shows the change in EC50 values as a function of irradiation dose. Clearly, EC50 values (data labelled as no $\mathrm{H}_{2} \mathrm{O}_{2}$ ) increased gradually with increasing doses, which indicate that the toxicity of 2-CP is substantially reduced.

Our result is consistent with previously documented toxicology data for 2-CP, where high irradiation doses (0.4-1 kGy [33] and 5-20 kGy [25]) caused a reduction of the toxicity of the target compound. It should be noted that the toxicity of the decomposition by-products substantially increased below these irradiation doses (0.4-1 kGy and 5-20 kGy) $[25,33]$, indicating that some of the newly formed by-products (under low irradiation doses) could be more toxic than the parent compound. In the present study, no increase in the toxicology of the by-products is documented because the lowest irradiation dose is higher than the highest dose quoted by [25, 33]. We extended the toxicity investigation to cover other experimental conditions such as the relation between toxicity and by-products formed under the effect of a strong oxidizing agent or toxicity of the by-products formed under acidic or alkaline conditions, which will be discussed in the following sections. These

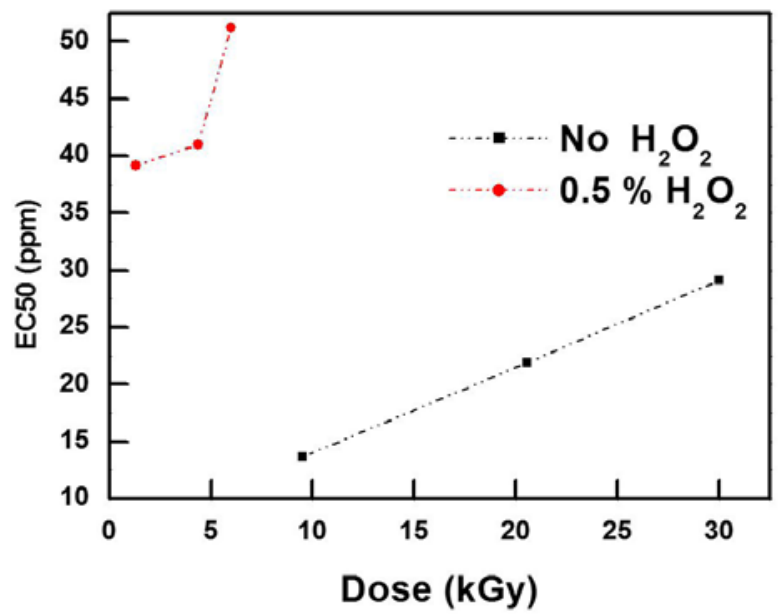

Fig. 5. Toxicity evaluation for $100 \mathrm{ppm}$ 2-CP represented as EC50 for different samples treated with three increasing doses. The figure also shows EC50 values vs. different irradiation doses for samples having $0.5 \% \mathrm{H}_{2} \mathrm{O}_{2}$.

investigations are particularly vital to guide the future implementation of the irradiation technology in this field.

\section{Effects of $\mathrm{H}_{2} \mathrm{O}_{2}$ on the toxicity of 2-CP}

In order to study the effect of $\mathrm{H}_{2} \mathrm{O}_{2}$ on toxicity, 2-CP at a concentration of $100 \mathrm{ppm}$ in neutral $\mathrm{pH}$ solution was spiked with $0.5 \% \mathrm{H}_{2} \mathrm{O}_{2}$ and irradiated at the previously determined $\mathrm{D}_{50}$ and $\mathrm{D}_{90}$ doses (associated with $0.5 \% \mathrm{H}_{2} \mathrm{O}_{2}$ ) and at an additional higher radiation dose $(6 \mathrm{kGy})$.

Figure 5 shows a comparison between EC50 values in the presence and absence of $0.5 \% \mathrm{H}_{2} \mathrm{O}_{2}$. Although irradiation dose range for both cases is not the same, we can confidentially conclude that the addition of $\mathrm{H}_{2} \mathrm{O}_{2}$ causes significant reduction because the toxicity of 2-CP at lower doses is lower than the samples with no $\mathrm{H}_{2} \mathrm{O}_{2}$ at higher doses. For example, as shown in Fig. 5, the EC50 value (47 ppm) for a sample with $\mathrm{H}_{2} \mathrm{O}_{2}$ that was irradiated at a dose of $6 \mathrm{kGy}$ is significantly higher than the EC50 value $(29 \mathrm{ppm})$ associated with the sample irradiated at $9.5 \mathrm{kGy}$ and contained no $\mathrm{H}_{2} \mathrm{O}_{2}$. It should be noted that the potential toxicity of $\mathrm{H}_{2} \mathrm{O}_{2}$ was eliminated prior to the toxicity experiments by adding $\mathrm{MnO}_{2}$ to the investigated solutions [30]. The fact that $\mathrm{MnO}_{2}$ did not exhibit toxicity and no change in the intensity of luminescent $V$. fischeri bacteria was confirmed. The toxicity results are consistent with our initial degradation experiments (Section " $\mathrm{H}_{2} \mathrm{O}_{2}$ oxidizer" and Fig. 2) that the addition of $\mathrm{H}_{2} \mathrm{O}_{2}$ enhances the decomposition of 2-CP molecules. The toxicity results also confirm that the toxicity of the oxidation by-products produced under gamma irradiation treatment with $\mathrm{H}_{2} \mathrm{O}_{2}$ is substantially reduced.

\section{Effects of $\mathrm{pH}$ of aqueous solutions on the toxicity} of 2-CP

Toxicology studies were extended to investigate the effect of various $\mathrm{pH}$ levels of 2-CP solutions with a concentration of $100 \mathrm{ppm}$. The effect on the toxicity 


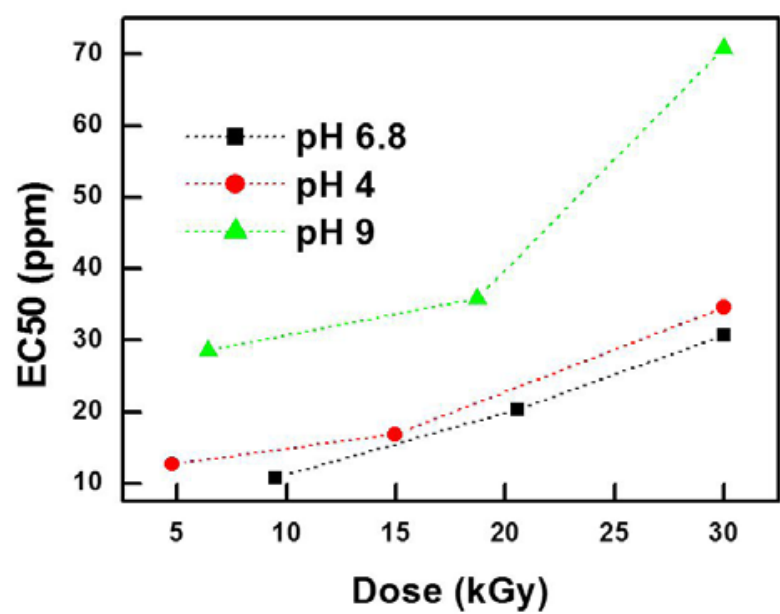

Fig. 6. Toxicity evaluation for $100 \mathrm{ppm}$ 2-CP represented as EC50 for different samples with different $\mathrm{pHs}$ irradiated at three increasing doses.

was evaluated based on the change in EC50 values. Figure 6 shows different datasets of EC50 values corresponding to different $\mathrm{pHs}$ plotted against different irradiation doses $\left(\mathrm{D}_{50}, \mathrm{D}_{90}\right.$, and $\left.30 \mathrm{kGy}\right)$. Consistent with the previously discussed removal efficiencies data presented in Fig. 3, changing the $\mathrm{pH}$ to acidic or alkaline conditions enhanced the degradation efficacy and consequently enhanced the reduction in the toxicity of $2-\mathrm{CP}$, seen as increased EC50 values in Fig. 6. However, it should be stated that the toxicity of 2-CP in acidic media ( $\mathrm{pH} 4)$ is reduced to a lesser degree compared to alkaline media $(\mathrm{pH} 9)$. These observations contradicted the observed trends in Fig. 3 that greater 2-CP degradation was accomplished at $\mathrm{pH} 4$ than at $\mathrm{pH} 9$. These discrepancies can be attributed to the fact that excess chloride ions in acidic media can present additional toxicity to $V$. fischeri bacteria and compensate the reduction in 2-CP toxicity [40, 41].

\section{Conclusions}

This study presented a thorough investigation of the radiolytic degradation of 2-CP in aqueous solutions by ionizing gamma radiation. A dose-dependent degradation was established with at least $90 \%$ of 2-CP concentrations being removed at an irradiation dose as low as $25 \mathrm{kGy}$. To validate the economic and technical viability of irradiation technology in water treatment processes, the effect of various experimental conditions such as adding $\mathrm{H}_{2} \mathrm{O}_{2}$ and varying the $\mathrm{pH}$ of the media to acidic or alkaline was investigated. The addition of $\mathrm{H}_{2} \mathrm{O}_{2}$ to 2-CP solutions reduced the required dose to achieve $90 \%$ removal to at least 1.3 -fold. The reduction in radiation doses was also observed in acidic and alkaline media, bringing the required doses of $90 \%$ removal to at least 0.4 -fold. Furthermore, the oxidation by-products have been elucidated, using HPLC and IC, and found to be primarily phenol molecules and chloride ions. Toxicology bioassay experiments were conducted. It was concluded that irradiating the samples with increasing doses gave positively proportional reduction in the toxicity of 2-CP and the toxicity reduction could be enhanced by adding a strong oxidizer such as $\mathrm{H}_{2} \mathrm{O}_{2}$ and changing the $\mathrm{pH}$ to acidic or alkaline conditions. These findings will contribute to the implementation of gamma irradiation technology to eliminate biologically resistant compounds from water.

Acknowledgments. The authors would like to acknowledge the support from the King Abdulaziz City for Science and Technology (KACST) in funding this project.

\section{References}

1. Czaplicka, M. (2004). Sources and transformations of chlorophenols in the natural environment. Sci. Total Environ., 322(1/3), 21-39. DOI: 10.1016/j. scitotenv.2003.09.015.

2. Michałowicz, J., \& Duda, W. (2007). Phenols sources and toxicity. Pol. J. Environ. Stud., 16(3), 347-362. DOI: 10.105 PJ 12301485.

3. Igbinosa, E. O., Odjadjare, E. E., Chigor, V. N., Igbinosa, I. H., Emoghene, A. O., Ekhaise, F. O., \& Idemudia, O. G. (2013). Toxicological profile of chlorophenols and their derivatives in the environment: The public health perspective. Sci. World J., 2013, 1-11. DOI: Artn 460215 \rDoi 10.1155/2013/460215.

4. Boulding, J. R., \& Ginn, J. S. (2004). Practical handbook of soil, vadose zone, and ground-water contamination: Assessment, prevention, and remediation (2nd ed.). Boca Raton: Lewis Publishers.

5. Ettala, M., Koskela, J., \& Kiesila, A. (1992). Removal of chlorophenols in a municipal sewage-treatment plant using activated-sludge. Water Res., 26(6), 797-804. DOI: 10.1016/0043-1354(92)90011-r.

6. Gupta, V. K., Carrott, P. J. M., Ribeiro Carrott, M. M. L., \& Suhas. (2009). Low-cost adsorbents: Growing approach to wastewater treatment - a review. Crit. Rev. Environ. Sci. Technol., 39(10), 783-842. DOI: 10.1080/10643380801977610.

7. Henze, M. (2008). Biological wastewater treatment: Principles, modelling and design. UK: IWA Publishing.

8. Clara, M., Strenn, B., Gans, O., Martinez, E., Kreuzinger, N., \& Kroiss, H. (2005). Removal of selected pharmaceuticals, fragrances and endocrine disrupting compounds in a membrane bioreactor and conventional wastewater treatment plants. Water Res., 39(19), 4797-4807. DOI: 10.1016/j.watres.2005.09.015.

9. Cheremisinoff, N. P. (2002). Handbook of water and wastewater treatment technologies. Boston: Butterworth-Heinemann.

10. Andreozzi, R. (1999). Advanced oxidation processes (AOP) for water purification and recovery. Catal. Today, 53(1), 51-59. DOI: 10.1016/S0920-5861(99)00102-9.

11. Zhao, X. B., Wang, L., \& Liu, D. -H. (2007). Effect of several factors on peracetic acid pretreatment of sugarcane bagasse for enzymatic hydrolysis. J. Chem. Technol. Biotechnol., 82(5), 1115-1121. DOI: 10.1002/ jctb.1775.

12. Klavarioti, M., Mantzavinos, D., \& Kassinos, D. (2009). Removal of residual pharmaceuticals from aqueous systems by advanced oxidation processes. Environ. Int. 35(2), 402-417. DOI: 10.1016/j.envint.2008.07.009.

13. Badawy, M. I., Ghaly, M. Y., \& Gad-Allah, T. A. (2006). Advanced oxidation processes for the removal of organophosphorus pesticides from wastewater. Desalination, 194(1/3), 166-175. DOI: 10.1016/j. desal.2005.09.027. 
14. Keen, O., \& Linden, K. G. (2013). Degradation of antibiotic activity during $\mathrm{UV} / \mathrm{H}_{2} \mathrm{O}_{2}$ advanced oxidation and photolysis in wastewater effluent. Environ. Sci. Technol., 47(22), 13020-13030. DOI: 10.1021/ es402472x.

15. Azbar, N., Yonar, T., \& Kestioglu, K. (2004). Comparison of various advanced oxidation processes and chemical treatment methods for COD and color removal from a polyester and acetate fiber dyeing effluent. Chemosphere, 55(1), 35-43. DOI: 10.1016/j. chemosphere.2003.10.046.

16. Esplugas, S., Bila, D. M., Krause, L. G. T., \& Dezotti, M. (2007). Ozonation and advanced oxidation technologies to remove endocrine disrupting chemicals (EDCs) and pharmaceuticals and personal care products (PPCPs) in water effluents. $J$. Hazard. Mater., 149(3), 631-642. DOI: 10.1016/j. jhazmat.2007.07.073

17. Basfar, A. A., Mohamed, K. A., Al-Abduly, A. J., AlKuraiji, T. S., \& Al-Shahrani, A. A. (2007). Degradation of diazinon contaminated waters by ionizing radiation. Radiat. Phys. Chem., 76(8/9), 1474-1479. DOI: 10.1016/j.radphyschem.2007.02.055.

18. Basfar, A. A., Mohamed, K. A., Al-Abduly, A. J., \& Al-Shahrani, A. A. (2009). Radiolytic degradation of atrazine aqueous solution containing humic substances. Ecotox. Environ. Safe., 72(3), 948-953. DOI: 10.1016/j.ecoenv.2008.05.006.

19. Basfar, A. A., Khan, H. M., Al-Shahrani, A. A., \& Cooper, W. J. (2005). Radiation induced decomposition of methyl tert-butyl ether in water in presence of chloroform: Kinetic modelling. Water Res., 39(10), 2085-2095. DOI: 10.1016/j.watres.2005.02.019.

20. Basfar, A. A., Khan, H. M., \& Al-Shahrani, A. A. (2005). Trihalomethane treatment using gamma irradiation: Kinetic modeling of single solute and mixtures. Radiat. Phys. Chem., 72(5), 555-563. DOI: 10.1016/j.radphyschem.2004.04.137.

21. Pera-Titus, M., García-Molina, V., Baños, M. A., Giménez, J., \& Esplugas, S. (2004). Degradation of chlorophenols by means of advanced oxidation processes: A general review. Appl. Catal. B-Environ., 47(4), 219-256. DOI: 10.1016/j.apcatb.2003.09.010.

22. Taghipour, F., \& Evans, G. J. (1997). Radiolytic dechlorination of chlorinated organics. Radiat. Phys. Chem., 49(2), 257-264. DOI: 10.1016/S0969806X(96)00065-5.

23. He, Y., Liu, J., Lu, Y., \& Wu, J. (2002). Gamma radiation treatment of pentachlorophenol, 2,4-dichlorophenol and 2-chlorophenol in water. Radiat. Phys. Chem., 65(4/5), 565-570. DOI: 10.1016/ S0969-806X(02)00364-X.

24. Klanova, J., Klan, P., Heger, D., \& Holoubek, I. (2003). Comparison of the effects of UV, $\mathrm{H}_{2} \mathrm{O}_{2} / \mathrm{UV}$ and $\gamma$-irradiation processes on frozen and liquid water solutions of monochlorophenols. Photochem. Photobiol. Sci., 2(10), 1023-1031. DOI: 10.1039/b303483F.

25. Shim, S. B., Jo, H. J., \& Jung, J. (2009). Toxicity identification of gamma-ray treated phenol and chlorophenols. J. Radioanal. Nucl. Chem., 280(1), 41-46. DOI: 10.1007/s10967-008-7388-z.

26. Trojanowicz, M., Chudziak, A., \& Bryl-Sandelewska, T. (1997). Use of reversed-phase HPLC with solidphase extraction for monitoring of radiolytic degradation of chlorophenols for environmental protection. I. Radioanal. Nucl. Chem., 224(1/2), 131-136. DOI: 10.1007/BF02034625.

27. Miller, A. (2000). Techniques for high dose dosimetry in industry, agriculture and medicine. Radiat.
Phys. Chem., 58(3), 305. DOI: 10.1016/S0969806X(99)00513-7.

28. Jankowska, A., Biesaga, M., Drzewicz, P., Trojanowicz, M., \& Pyrzyńska, K. (2004). Chromatographic separation of chlorophenoxy acid herbicides and their radiolytic degradation products in water samples. Water Res., 38(14/15), 3259-3264. DOI: 10.1016/j. watres.2004.03.032.

29. Lewins, J., \& Becker, M. (1999). Advances in nuclear science and technology. New York: Springer.

30. Weihua, S., Zheng, Z., Rami, A. S., Tao, Z., \& Desheng, H. (2002). Degradation and detoxification of aqueous nitrophenol solutions by electron beam irradiation. Radiat. Phys. Chem., 65(4/5), 559-563. DOI: 10.1016/S0969-806X(02)00365-1.

31. Borrely, S. I., Sampa, M. H. O., Pedroso, C. B., Oikawa, H., Silveira, C. G., Cherbakian, E. H., \& Santos, M. C. F. (2000). Radiation processing of wastewater evaluated by toxicity assays. Radiat. Phys. Chem., 57(3/6), 507-511. DOI: 10.1016/S0969-806X(99)00418-1.

32. Steinberg, S. M., Poziomek, E. J., Engelmann, W. H. \& Rogers, K. R. (1995). A review of environmental applications of bioluminescence measurements. Chemosphere, 30(11), 2155-2197. DOI: 10.1016/00456535(95)00087-O.

33. Zona, R., Schmid, S., \& Solar, S. (1999). Detoxification of aqueous chlorophenol solutions by ionizing radiation. Water Res., 33 (5), 1314-1319. DOI: 10.1016/ S0043-1354(98)00319-4.

34. Yang, R., Wang, M., Shen, Z., Wang, W., Ma, H., \& $\mathrm{Gu}$, J. (2007). The degradation and mineralization of 4-chlorophenol in aqueous solutions by electron beam irradiation in the presence of $\mathrm{TiO}_{2}$ nanoparticles. Radiat. Phys. Chem., 76(7), 1122-1125. DOI: 10.1016/j.radphyschem.2006.10.008.

35. Gogate, P. R., \& Pandit, A. B. (2004). A review of imperative technologies for wastewater treatment I: Oxidation technologies at ambient conditions. Adv. Environ. Res., 8(3/4), 501-551. DOI: 10.1016/ S1093-0191(03)00032-7.

36. Schmid, S., Krajnik, P., Quint, R. M., \& Solar, S. (1997). Degradation of monochlorophenols by $\gamma$-irradiation. Radiat. Phys. Chem., 50(5), 493-502. DOI: 10.1016/S0969-806X(97)00075-3.

37. Torun, M., Abbasova, D., Solpan, D., \& Guven, O. (2014). Caffeine degradation in water by gamma irradiation, ozonation and ozonation/gamma irradiation. Nukleonika, 59(1), 25-35. DOI: 10.2478/ nuka-2014-0004.

38. Getoff, N., \& Solar, S. (1986). Radiolysis and pulse radiolysis of chlorinated phenols in aqueous solutions. Int. J. Radiat. Appl. Instrum. Part C-Radiat. Phys. Chem., 28(5/6), 443-450. DOI: 10.1016/1359$0197(86) 90165-7$.

39. Parvez, S., Venkataraman, C., \& Mukherji, S. (2006). A review on advantages of implementing luminescence inhibition test (Vibrio fischeri) for acute toxicity prediction of chemicals. Environ. Int., 32(2), 265-268. DOI: 10.1016/j.envint.2005.08.022.

40. Stafford, U., Gray, K. A., \& Kamat, P. V. (1994). Radiolytic and $\mathrm{TiO}_{2}$-assisted photocatalytic degradation of 4-chlorophenol. A comparative study. J. Phys. Chem., 98(25), 6343-6351. DOI: 10.1021/j100076a019.

41. Trojanowicz, M., Drzewicz, P., Pańta, P., Gluszewski, W., Nalecz-Jawecki, G., Sawicki, J., Szewczyńska, M. (2002). Radiolytic degradation and toxicity changes in $\gamma$-irradiated solutions of 2,4-dichlorophenol. $R a$ diat. Phys. Chem., 65(4/5), 357-366. DOI: 10.1016/ S0969-806X(02)00336-5. 